\title{
Delayed Presentation of Right-Sided Congenital Diaphargmatic Hernia Case Report
}

\author{
Mohammad H. \\ Department of Radiology, Benue State University Teaching Hospital, Makurdi, Nigeria. \\ E-mail:drhameed2001@yahoo.com
}

\begin{abstract}
Congenital diaphragmatic hernia (CDH) commonly occurs on the left and the patients usually present during neonatal period with respiratory distress. Rarely, the condition may occur on the right and the presentation may be delayed. This is a report of a patient with a right sided CDH who presented at three months but the correct diagnosis was at six months.
\end{abstract}

\section{Introduction:}

The diaphragm is a strong muscle of respiration that also serves to separate the abdominal viscera from the thorax. Congenital herniation of abdominal viscera into the thorax may occur through a defect or potential space in the diaphragm. This defect that permits the herniation may occur on the right, left, both sides, anterior median or through oesophageal hiatus of the diaphragm $^{1,2}$.

The incidence of Congenital Diaphragmatic Hernia (CDH) varies between 1 in 2,000 to 1 in 5,000 live births. The hernia is twice more common in males than females and a $20 \%$ incidence among sibling or parents who had $\mathrm{CDH}$ have been documented ${ }^{2-4}$.

Though the etiology of CDH is unknown, certain drugs such as thalidomide and nitrofuratoin have been implicated. Also gene mutation and a variety of chromosomal anomalies like trisomy 12 , trisomy 13 and trisomy 18 have known to be associated $\mathrm{CDH}^{2,4}$.

In addition to the chromosomal abnormalities, congenital anomalies of the genitourinary, cardiovascular, gastrointestinal and the central nervous system may also co-exist with $\mathrm{CDH}^{2}$.

$\mathrm{CDH}$ usually present in the early neonatal period as a case of severe respiratory distress but in some rare cases, the presentation may be delayed ${ }^{5,6}$.

This is a report of a case of a 6-month-old female infant with right sided $\mathrm{CDH}$ who first presented with respiratory distress at 3 month. But the correct diagnosis was only made when she was 6 months old.

\section{Case Report:}

N.A. is a 6-month-old female infant who was brought by her parents to the paediatric outpatient department of the University of Maiduguri Teaching Hospital (UMTH), Maiduguri, with complaints of cough, difficulty in breathing and weight loss all for about three months duration. Prior to presentation, the patient had been taken to numerous hospitals where she was diagnosed as a case of recurrent bronchopneumonia. Despite the treatment she received in these hospitals, the symptoms kept on getting worse.

The patient is the only child in a monogamous setting. The father is a supervisor in a construction company, while the mother is a full time house wife. There is no history of chronic illness or congenital abnormalities in the family. The pregnancy was booked at 3 month. The antenatal history was uneventful. The mother claimed that her antenatal ultrasound was normal. Patient was delivered by spontaneous vaginal delivery at 36 weeks in a private hospital and she cried at birth. Patient is not up to date with her immunization. According to the mother, this was due to the patient's recurrent illness.

Physical examination revealed an infant who was calm, acyanosed, afebrile to touch and not jaundiced. Respiratory rate was $40 / \mathrm{mins}$. There was decrease air entry on the right lung on auscultation. Cardiovascular examination revealed a pulse rate of 122 beats $/ \mathrm{min}$. On auscultation of the heart there was a shift of cardiac sounds towards the left axilla. The heart sounds were 1 and 2 only. Abdominal examination showed a scaphoid abdomen. There was no palpably enlarged organ. All other systems were normal. Her haemogram, Urinalysis, serum electrolytes and urea were all normal.

Plain radiograph of the chest, anteriorposterior view, showed gas distended bowel loops in the right hemi thorax. There was none visualization of the diaphragmatic margin on that side. There was a shift of the heart and the mediasternum to the contralateral side (fig. 1). The lateral radiograph of the chest showed the bowel loops to be posterior to the heart. (radiograph not shown). Barium enema 
study showed the hepatic and transverse fissure to be in the thorax posterior to the heart (fig. 2). Abdominal ultrasound showed some bowel loops and part of the liver in the right hemithorax (fig. 3). The remaining intra abdominal organs were normal. Transfontanel sonography and echocardiography were also normal.

A diagnosis of a right sided diaphragmatic hernia was made. At surgery, the right lung was hypoplastic, the hepatic flexure, transverse colon; small intestine and part of the liver were seen in the right hemi thorax through a $6 \mathrm{~cm} \times 4 \mathrm{~cm}$ defect. Multiple areas of adhesions between the small intestines and posterior portion of the diaphragm; and between the colon and greater omentum were seen. The defect was repaired after the herniated structures were reduced into the abdomen. The adhesions were freed. Post operative check radiograph and $\mathrm{PCV}$ showed a remarkable improvement and the patient was discharged home after 16 days post operative. Follow up at paediatric surgical outpatient department showed the patient to be doing well.

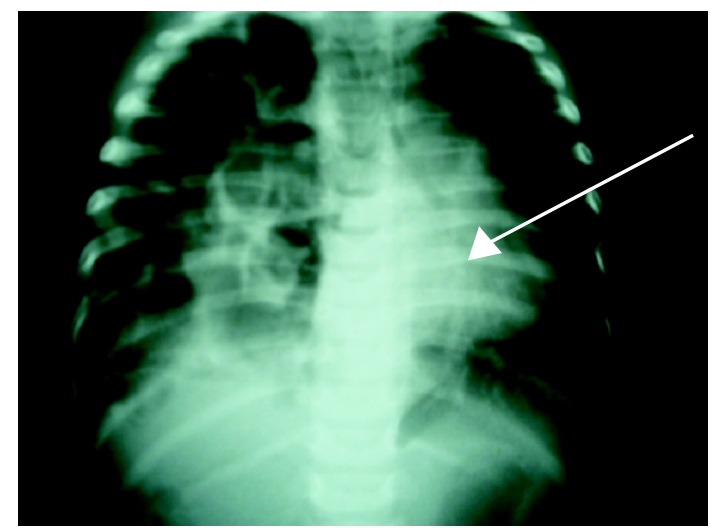

Figure 1: Plain chest radiograph, anteriorposterior view, showing multiple gas filled bowel loops in the right hemithorax (white arrow). The heart is shifted to the left (black arrow).

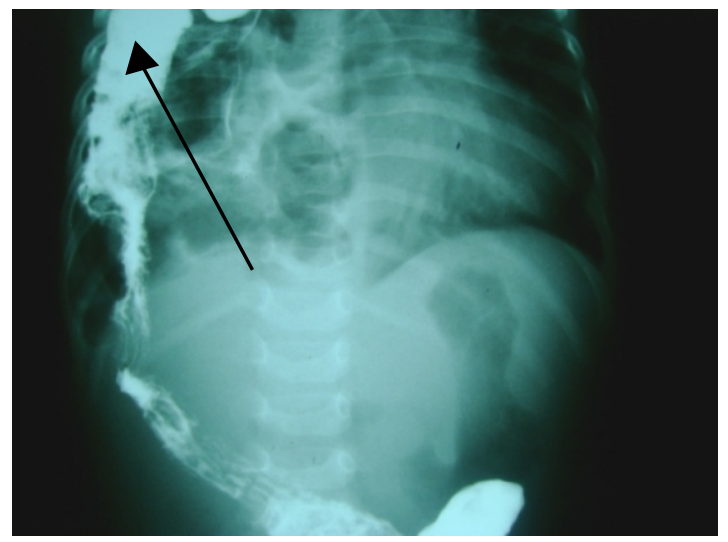

Figure 2: Barium enema showing opacified large bowel in the right hemithorax (arrow).

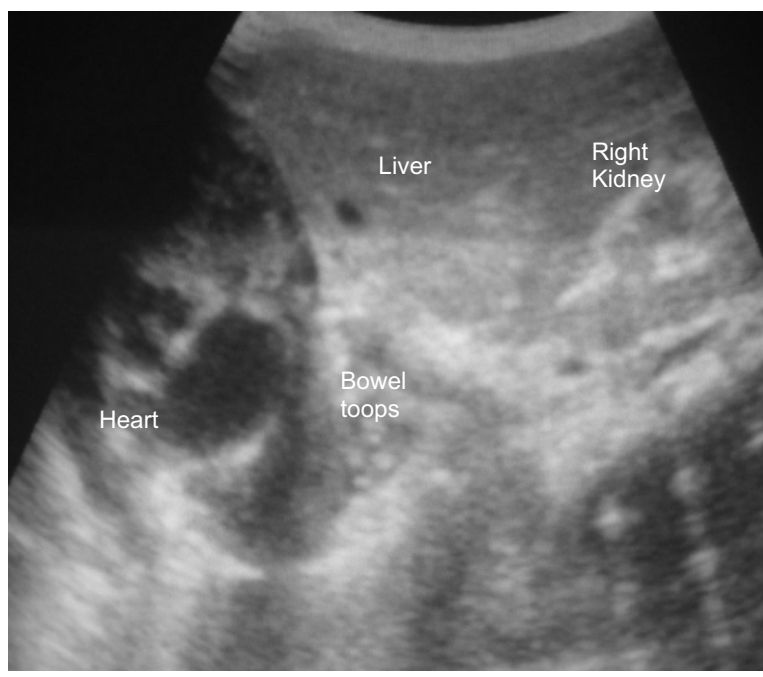

Figure 3: Trans upper abdominal ultrasound showing part of the liver and some bowel loops in the right hemithorax adjacent the heart.

\section{Discussion}

$\mathrm{CDH}$ is classified into three types: the posterior lateral (Bochdalek) which occurs through the posterior pleuroperitoneal communication of Bochdalek, the Morgagni hernia which occurs in the anterior midline through the sternocostal hiatus of the diaphragm and the hiatus hernia which occurs through the oesophageal hiatus ${ }^{2}$. Among all these, Bochdalek is the most common type of diaphragmatic hernia and it is also 5 times more common on the left than the right ${ }^{6,7}$. This patient presented with a right sided Bochdalek hernia.

The clinical presentation of patient with $\mathrm{CDH}$ depends on the size of the defect and the associated anomalies. The patient most often present early in the neonatal period with respiratory distress and scaphoid abdomen if the defect is large ${ }^{7}$. Occasionally, there may be delayed presentation, especially if the defect is small or if the defect is on the right ${ }^{5}$. It is postulated that the liver may somehow plug the defect ${ }^{5,7}$. It has also been noted that poor lung compliance and assisted ventilation may also delay the appearance. This case under study had a delayed presentation at 3-month. The reason may be because before then the defect was plugged by the liver. Though, when she presented with the symptoms at 3-months the diagnosis was missed. The reason may not be unconnected with the rarity of CDH. Hence a high index of suspicion is needed by the clinician in order to clinch the diagnosis.

$\mathrm{CDH}$ is associated with a wide range of complications. These include: pulmonary hypoplasia, gastric volvulus, rotational 
abnormalities, and bilateral renal hypertrophy and ladd bands $\mathrm{s}^{7,8}$. Apart from pulmonary hypoplasia and ladd's band, none of these complications were seen in this patient.

In the evaluation of patient with $\mathrm{CDH}$, imaging studies play a crucial role ${ }^{2,5,9}$. The timing of these studies could be in the prenatal or postnatal period" ${ }^{10}$. Prenatal ultrasonography in pregnant women carrying a fetus with $\mathrm{CDH}$ relies on detecting abdominal organs in the chest of the fetus. But the sonographic hall mark is a fluid filled mass behind the left ventricle. Other sonographic features include polyhydraminious, a mediasternal shift, a small abdominal circumference and the detection of stomach in the fetal chest ${ }^{9}$. These features were missed during antenatal visit in this case report.

Other prenatal radiological investigations include fetal echocardiogram and ultra fast fetal $\mathrm{MRI}^{4,11}$.

In the post natal diagnosis of $\mathrm{CDH}$, plain chest radiograph is paramount ${ }^{7}$. In the early neonatal period before air enters the bowel, the fluid filled diaphragmatic hernia produces a large opaque hemithorax. After air is swallowed and is passed through the intestinal tract, loops of bowel in the hernia become gas filled. Placement of an enteric tube verifies that there is bowel in the chest rather than a primary chest mass ${ }^{5,7,12}$. This patient's chest radiograph showed bowel in the right hemithorax.

Though, the diagnosis of CDH is now frequently made prenatally at antenatal ultrasound, ${ }^{9,}$, this patient presented at 6-month in this hospital. The postnatal ultrasound confirmed the diagnosis of the right diaphragmatic hernia.

Other imaging studies that may be employed in the post natal period include: barium study, CT and $\mathrm{MRI}^{7,11,12}$. The barium enema of this patient further confirmed the diagnosis. Post natal CT and MRI, though important were not done for this patient because of cost.

The management of $\mathrm{CDH}$ is surgical. In the neonatal and infantile periods, the classic timing of surgical repair depends on the infant's condition ${ }^{13}$. An important variable in the surgical management is the degree of underlying lung under development. Often, the repair is delayed until the infant has stabilized which could take hours, a few days or few weeks ${ }^{13,14}$. If the infant's condition deteriorates, extra-corporeal membrane oxygenation (ECMO) can be instituted and in some cases, repair can be done while the infant is on
ECMO. Weaning from ECMO can occur post operatively ${ }^{14}$. This patient had right lung hypoplasia but she was stable enough to undergo the surgery after the laboratory and radiological evaluation.

In conclusion, $\mathrm{CDH}$ may present as a major surgical emergency in the early neonatal period. But late presentation may also occur. Therefore, a high index of suspicion coupled with appropriate radiological investigations are necessary to clinch the diagnosis.

\section{References:}

1. Torfs CD, Curry CJ, Bateson TF, Honore LH. A population based study of congenital diaphragmatic hernia. Teratology 1992; 46:55 620.

2. Dahnert W. Chest disorders. Radiology Review Manual. $4^{\text {th }}$ edn. Lippincott Williams and Wilkins. Philadelphia PA. 1991; Pp 1316-3287.

3. Pober BR, Lin A, Russell M, Ackerman KG. Infants with Bochdalek diaphragmatic hernia; sibling recurrence and monozygotic twin discordance in a hospital based malformation surveillance program. Am J Med Genet A 2005; 1381:8190.

4. Witters I, Legius E, Moerman P, Deprest J. Associated malformations and chromosomal anomalies in 42 cases of prenatally diagnosed diaphragmatic hernia. Am J Med Genet 2006; 103:278 360.

5. Murffit J. The normal chest: Methods of investigation and differential diagnosis. In: David S.(ed). A text book of Radiology and Imaging. $7^{\text {th }}$ edn. Churchill Livingstone. Edinburgh. 2002; Pp 53-54.

6. Nitecki S, Bar-Maor JA. Late presentation of Bochdalek hernia: Our experience and review of the literature. Isr J Med Sci 1992; 28: 711715.

7. Kirks RD, Caron KH. Gastrointestinal tract. In: Kirks RD, Harwood-Nash CD. Practical Pediatric ImagingDiagnostic Radiology of Infants and Children. $2^{\text {nd }}$ edn. Little, Brown and Company. Boston. 1991; Pp 742-744.

8. Real JO. Long EF. Diaphragmatic hernia in infancy. Am J Roentgenol 1959; 82:437.

9. Dillon E, Renwick M, Wright C. Congenital diaphragmatic herniation: Antenatal detection and outcome. Br J Radiol 2000; 73:360 365 .

10. Albanese CT, Lopoo J, Goldstain RB, Filley RA. Fetal liver position and perinatal outcome for congenital diaphragmatic hernia. Prenat Diagn. 1998; 18: 11381180.

11. Matsuoko S, Takeuchi K, Yamanaka Y, Kaji Y. Comparison of magnetic resonance imaging and ultrasonography in the prenatal diagnosis of congenital thoracic abnormalities. Fetal Diagn ther 2003; 18: 447500.

12. Flower CDR. The diaphragm. In: Grainger RG and Allison DJ. Diagnostic Radiology-An Anglo American Textbook of Imaging. $2^{\text {nd }}$ edn. Churchill Livingstone. London. 1993; Pp177-182.

13. Downard CD, Jaksic T, Garza JJ. Dzakovic A. Analysis of an improved survival rate for congenital diaphragmatic hernia. J Pediatr Surg 2003; 38: 729-761.

14. Harrington KP and Goldman AP. The role of extracorporeal membrane oxygenation in congenital diaphragmatic hernia. Semin Pediatr Surg 2005; 14: 7278. 